\title{
IS IT WORTH TO REUSE THE NITINOL ARCH WIRES?
}

Hala M. Abdel Majeed*,

\author{
Ahmed E.A. Salama**, Dina H. Mostafa ${ }^{* * *}$
}

ABSTRACT

Objective: Is to investigate the effect of different methods of sterilization (autoclave sterilization, cold chemical disinfection solution (CIDEX) and gas sterilization) on the bending properties of nickel titanium arch wires. The surface roughness and the elemental analysis measurements of the passive layer were also performed to verify if it is possible to reuse these sterilized nickel titanium arch wires. Material and Methods: Seventy nickel titanium arch wires were used: ten control specimens (unused and unsterilized group). Thirty specimens unused, of which each ten specimens were subjected to a different method of sterilization: a-Autoclave. 6-Cold chemical disinfection solution using CIDEX. c- Gas sterilization. The last thirty specimens were clinically used and subjected to the three methods of sterilization previously mentioned. All specimens were tested under three point loading test using a universal testing machine with a cross head speed of $0.5 \mathrm{~mm} / \mathrm{mn}$. The atomic force microscopy (AFM) was used to analyze in three-dimension the surface topography and the surface roughness (Ra) of the alloy and energy dispersive $X$-ray analysis (EDX) was used to identify quantitatively and qualitatively the elements present on the

\footnotetext{
* Assistant professor Orthodontic Department, Faculty of Oral and Dental Medicine, Cairo University.

** Lecturer Orthodontic Department, Faculty of Dental Medicine, El Azhar University Girls branch.

*** Assistant professor Biomaterials Department, Faculty of Oral and Dental Medicine, Cairo University.
} 
Egyptian

Orthodontic Journal

surface of the nickel titanium arch wires. Results: Comparing the control group with the unused sterilized arch wires; it was found that there were insignificant differences in the maximum bending strength, maximum deflection property and the modulus of elasticity between the control group and the unused autoclave and gas sterilized arch wires. There was a significant drop in the modulus of elasticity of the unused sterilized arch wires disinfected with cold chemical solution (CIDEX). Comparing the control group with the clinically used sterilized arch wires as well as, the unused with the clinically used sterilized arch wires, it was found that a statistically significant high maximum bending strength of the clinically used autoclave and gas sterilized arch wires groups from the control group. The maximum deflection property and the modulus of elasticity showed insignificant results. The AFM image of nickel titanium surfaces indicates increase in roughness and change in surface topography of the passive layer after cold chemical disinfection solution. The EDDX analysis results showed that the elements of the outermost surface of the passive film on all nickel titanium arch wires were all the same after different methods of sterilization. Conclusions: 1 - It is worth to reuse the nickel-titanium arch wires due to its high cost. 2- Autoclave and gas sterilization did not affect the nickel titanium alloy. 3- Chemical sterilization may alter the topography of nickel titanium alloy and consequently affects its bending property. 4- Mechanical forces during the usage affect the maximum bending strength of arch wires.

\section{INTRODUCTION}

Orthodontic arch wires are designed to move teeth with light continuous forces. Mechanotherapy depends on both the elastic behavior of the material and the biochemical reaction of the teeth ${ }^{1}$. It is the aim of all clinicians to accomplish biological tooth movement, which implies the use of low, continuous force and requires arch wire with low stiffness. Nickel Titanium was felt more appropriate 
for intraoral use than stainless steel, it is the most biocompatible material, it has high resistance to corrosion, it exhibits unique physical properties of increased elasticity and resilience and greater working range, which allows arch wires to sustain large elastic deflections due to the very high springback quality ${ }^{2}$. Rotations of teeth could be accomplished without increasing patient discomfort and avoiding the need for complex loops ${ }^{3}$.

The nickel titanium alloy was named nitinol, an acronym for the elements from which the material was composed; Ni for nickel, Ti for titanium and NOL from the Naval Ordnance Laboratory. The nitinol alloys have an inherent ability to alter their type of atomic bonding which causes unique and significant changes in the mechanical properties and crystallographic arrangement of the alloy. These changes occur as a function of temperature and stress. The two unique features that are of relevance to clinical dentistry occur as a result of the austenite to martensite transition in the nitinol alloy; these characteristics are termed shape memory and superelasticity. Superelasticity is a property used in orthodontics to initiate tooth movement in the first stage of orthodontic treatment. The majority of these arch wires appear undistorted with excellent corrosion resistance when removed from the mouth after use. This feature, has encouraged clinicians to sterilize and recycle these arch wires ${ }^{4,5,6,7,8}$. In addition, reuse of nitinol arch wires has been advocated because of the high costs of these materials ${ }^{9,10}$.

The American Dental Association, the center for Disease Control and Prevention, and the Food and Drug Administration require that reusable dental instruments and components be sterilized after each use in a patient ${ }^{11,12}$. Sterilization is a process intended to kill all microorganisms, including spores; it is the highest level of microbial kill that can be achieved ${ }^{13}$. The adequate sterilization of reusable instruments and components is essential to prevent cross contamination between patients ${ }^{14}$. While disinfection using cold chemical solutions refers only to the inhibition or killing of pathogens, however all spores may not be killed during disinfection ${ }^{15}$.

It is difficult in case of disinfection using cold chemical solutions to control the use of adequate immersion time and the changing of solutions when required. Unlike gas or heat sterilization, disinfectants take several hours to sterilize (unless heated) and cannot be verified for sterilization in office use. To insure the destruction of all pathogens, heat sterilization is the method of choice. For those practitioners who use chemical solutions to disinfect or sterilize their arch wires, neither the elastic properties nor the surface topographies appear to be compromised ${ }^{16}$. The choice of disinfectants depends on the type of surface to 
be disinfected. Incorrect application of disinfectants may affect the physical and/or mechanical properties of materials undergoing the disinfection process ${ }^{17}$. While rigorous cleaning operations are performed on the processed metal to remove contamination, the effects of these aggressive manufacturing conditions on the corrosion resistance of nitinol remain unclear ${ }^{18}$. The aim of this study is to investigate the effect of different methods of sterilization: autoclave sterilization, cold chemical disinfection solution (CIDEX) and gas sterilization on the bending properties of nickel titanium arch wires. Topographical study and surface roughness measurements as well as qualitative and quantitative elemental analysis of the passive layer of these nickel titanium arch wires were employed to verify if it is possible to reuse these sterilized nitinol arch wires.

\section{Material and Methods:}

Seventy nickel titanium arch wires 0.016 inch in diameter (Rematitan Lite Dimple: Dentaurum, Pforzheim, Germany.Batch No 21307) were included in the study, which were subjected to various sterilization and disinfection procedures. Thirty of those arch wires were clinically used to treat patients for one to three months. The remaining arch wires were subjected to these sterilization procedures only to differentiate between the effects of different sterilization procedures before and after clinical use on the behavior of these arch wires.

\section{Specimens sterilization:}

All arch wires were divided equally into seven groups comprising 10 arch wires in each group. These included group I: new unused arch wires and group II clinically used arch wires were steam autoclaved. Group III: new unused arch wires and group IV: clinically used arch wires were cold disinfection in two per cent glutaraldehyde solution (CIDEX)(Johnson and Johnson, Medical Inc. The abbreviation of EXcellent bacterioCIDal). Group V: new unused arch wires and group VI: clinically used arch wires were gas sterilized. Group VII: were set as received to serve as the control group. In groups I and II, all arch wires were steam autoclaved (M7 speedclave midmark USA.), where each wire was individually wrapped in clear sterilization bags. Total cycle time was 15 minutes, at a sterilization temperature of $134.4^{\circ} \mathrm{C}$, which was maintained for 10 minutes. In groups III and IV, all arch wires were sterilized in freshly prepared $2 \%$ acidic glutaraldehyde cold chemical disinfection solution (CIDEX) for 10 hours which is ADA approved and was used at concentrations recommended for sterilization by the manufacturer. After sterilization, the arch wires were rinsed off in running water, laid on absorbent paper, and allowed to air dry. Groups V and VI, were individually wrapped in clear sterilization bags and sterilized by ethylene oxide at $54.44^{\circ} \mathrm{C}$ for 24 hours.

Volume 30 - December 2006 
Egyptian

Orthodontic Journal

\section{Mechanical Testing:}

All arch wires were subjected to the bending test on a universal testing machine (model LRX, Lloyd Instrument Ltd, Fareham, England), at a speed of $0.5 \mathrm{~mm} / \mathrm{mn}$. Loading curves were obtained for all specimens and the results of the maximum bending strength test were calculated from the formula ${ }^{19}$ :

$\sigma=\frac{8 P L}{\pi d^{3}}$

where: $\sigma$ is the maximum bending strength.

$\mathrm{P}$ is the maximum load.

$\mathrm{L}$ is the length of $\operatorname{span}(2 \mathrm{~mm})$.

$\pi$ is 3.14 .

$\mathrm{d}$ is the diameter of the wire $(0.4064 \mathrm{~mm})$.

While the modulus of elasticity was calculated from the formula ${ }^{19}$ :

$E=\frac{4}{3} \frac{P L^{3}}{\pi d^{4} \delta}$

where $\mathrm{E}$ is the modulus of elasticity.

$\delta$ is the maximum deflection.

Data were presented as mean and standard deviation values. One-way Analysis of Variance (ANOVA) test followed by Dunnett's test was used to compare the maximum bending strength, maximum deflection and modulus of elasticity between control and experimental groups. One-way ANOVA followed by Duncan's test was used to compare the maximum bending strength, maximum deflection and modulus of elasticity between the experimental groups. The significance level was set at $P \leq 0.05$. Statistical analysis was performed with SPSS $13.0^{20}$.

\section{Topographical study:}

Atomic force microscopy (AFM) was used (Thermomicroscopes Autoprobe $\mathrm{CP}$ research, scanner $100 \mu \mathrm{m}$, USA.) to analyze the three-dimensional surface topography and measure the average surface roughness ( $\mathrm{Ra})$ of the arch wires after different sterilization procedures. 
Egyptian

Orthodontic Journal

\section{Elemental Analysis:}

Energy Dispersive X-ray Analysis (EDX) (SEM model Philips XL 30 attached with EDX unit, with accelerating voltage $30 \mathrm{~K}$.V., magnification 10x up to $400.000 \mathrm{x}$ and resolution for $\mathrm{w}$. $(3.5 \mathrm{~nm})$ ) was done to analyse quantitatively and qualitatively any changes at the elements present in the passive layer of the nitinol archwires after different sterilization procedures.

\section{RESULTS}

\section{I- The Mechanical Test:}

Table 1 and figure 1 compare the means, standard deviation values of ANOVA and Dunnett's test of the maximum bending strength, maximum deflection and modulus of elasticity between the control and unused sterilized arch wires groups.

There was no statistically significant difference between the control group and unused sterilized arch wires groups as regards the maximum bending strength $(P=0.251)$ and the maximum deflection $(P=0.057)$.

Table1: The means, standard deviation values of the maximum bending strength, maximum deflection and modulus of elasticity between the control and unused sterilized arch wires groups

\begin{tabular}{|c|c|c|c|c|c|c|}
\hline \multirow{2}{*}{ Group } & \multicolumn{2}{|c|}{$\begin{array}{c}\text { Maximum } \\
\text { bending }\end{array}$} & \multicolumn{2}{c|}{$\begin{array}{c}\text { Maximum } \\
\text { deflection }\end{array}$} & \multicolumn{2}{c|}{$\begin{array}{c}\text { Modulus of } \\
\text { elasticity }\end{array}$} \\
\cline { 2 - 7 } & $\begin{array}{c}\text { Mean } \\
\text { (MPa) }\end{array}$ & SD & $\begin{array}{c}\text { Mean } \\
(\mathbf{m m})\end{array}$ & SD & $\begin{array}{c}\text { Mean } \\
\text { (MPa) }\end{array}$ & SD \\
\hline $\begin{array}{c}\text { Control group } \\
\text { IIGroup V }\end{array}$ & 16308.2 & 803.1 & 5.9 & 0.97 & $8436.6^{\mathbf{b}}$ & 935.8 \\
\hline $\begin{array}{c}\text { Autoclave sterilization } \\
\text { Group I }\end{array}$ & 15684.3 & 1786.1 & 5.6 & 0.94 & $8441.3^{\mathbf{b}}$ & 570.5 \\
\hline $\begin{array}{c}\text { Cold chemical } \\
\text { disinfection (CIDEX) } \\
\text { Group III }\end{array}$ & 16105.1 & 108 & 8.6 & 1.9 & $5780.6^{\mathbf{a}}$ & 1163.6 \\
\hline $\begin{array}{c}\text { Gas sterilization } \\
\text { Group V }\end{array}$ & 17491.6 & 690.4 & 6.4 & 0.5 & $8285^{\mathbf{b}}$ & 409.7 \\
\hline P-VALUE & 0.251 & & 0.057 & & $0.010^{*}$ \\
\hline
\end{tabular}

SD: Standard Deviation, *: Significant at $\mathrm{P} \leq 0.05$, Means with different letters are statistically significantly different. 
As regards the modulus of elasticity Dunnett's test showed that there was a significant lower value for the cold chemical disinfection (CIDEX) group than the control group $(\mathrm{P}=0.010)$ while for the autoclave and gas sterilization groups the values were insignificantly different when compared with that of the control group.
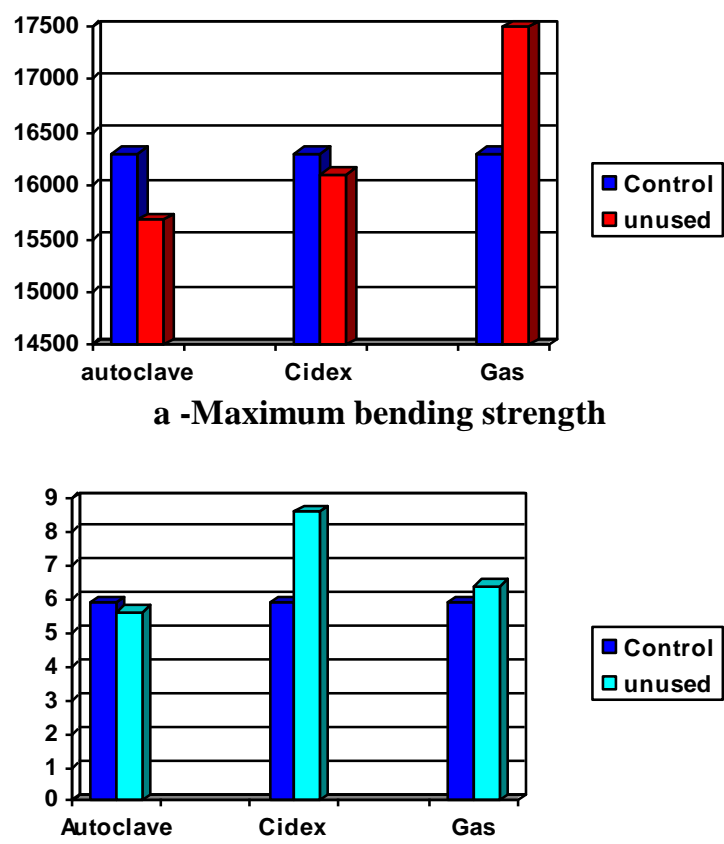

b- Maximum deflection

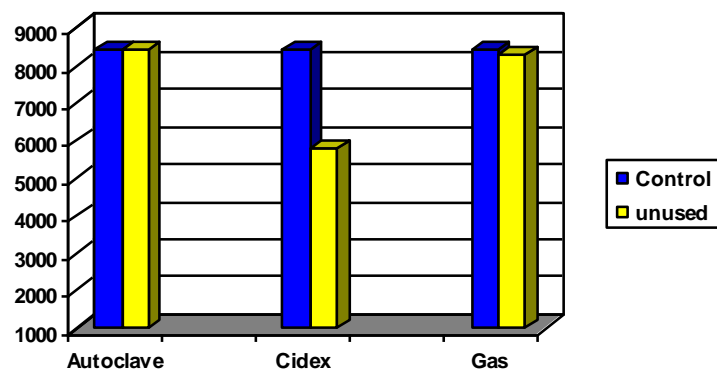

c- Modulus of elasticity

Figure 1: Comparison between the control and the unused sterilized nickel titanium arch wire groups a- maximum bending strength b- maximum deflection c-Modulus of elasticity 
Table 2 and figure 2 compare the means, standard deviation values and results of ANOVA and Dunnett's test of the maximum bending strength, maximum deflection and modulus of elasticity between control and clinically used sterilized arch wires groups.

Table 2: The means, standard deviation values of the maximum bending strength, maximum deflection and modulus of elasticity between the control and the clinically used sterilized arch wires groups.

\begin{tabular}{|c|c|c|c|c|c|c|}
\hline \multirow{2}{*}{ Measurement } & \multicolumn{2}{|c|}{ Maximum bending } & \multicolumn{2}{c|}{$\begin{array}{c}\text { Maximum } \\
\text { deflection }\end{array}$} & \multicolumn{2}{c|}{$\begin{array}{c}\text { Modulus of } \\
\text { elasticity }\end{array}$} \\
\cline { 2 - 7 } & $\begin{array}{c}\text { Mean } \\
(\text { MPa })\end{array}$ & SD & $\begin{array}{c}\text { Mean } \\
(\mathbf{m m})\end{array}$ & SD & $\begin{array}{c}\text { Mean } \\
(\text { MPa })\end{array}$ & SD \\
\hline $\begin{array}{c}\text { Control } \\
\text { Group VII }\end{array}$ & $16308.2^{\mathbf{a}}$ & 803.1 & 5.9 & 0.97 & 8436.6 & 935.8 \\
\hline $\begin{array}{c}\text { Autoclave sterilization } \\
\text { Group II }\end{array}$ & $20520.7^{\mathbf{b}}$ & 1555.3 & 5.8 & 0.3 & 1052.7 & 326.5 \\
\hline $\begin{array}{c}\text { Cold chemical } \\
\text { disinfection (CIDEX) } \\
\text { Group IV }\end{array}$ & $15384.6^{\mathbf{a}}$ & 3063.7 & 5.02 & 0.5 & 9349.4 & 2797.1 \\
\hline $\begin{array}{c}\text { Gas sterilization } \\
\text { Group VI }\end{array}$ & $20498.7^{\mathbf{b}}$ & 2195.3 & 8.2 & 3.5 & 8067.6 & 2251 \\
\hline $\boldsymbol{P}$-VALUE & $0.029 *$ & \multicolumn{2}{|c|}{0.245} & & 0.425 \\
\hline
\end{tabular}

SD: Standard Deviation, *: Significant at $\mathrm{P} \leq 0.05$, Means with different letters are statistically significantly different.

There was no statistically significant difference between the control group and clinically used sterilized arch wires groups as regards the maximum deflection $(P=0.245)$ and the modulus of elasticity $(P=0.425)$.

As regards the maximum bending strength, Dunnett's test showed that there was a significant higher value of the maximum bending strength for the autoclave and gas sterilization than the control group $(\mathrm{P}=0.029)$, while for the cold chemical disinfection (CIDEX) group the value was insignificantly different from the control group. 
Egyptian

Orthodontic Journal

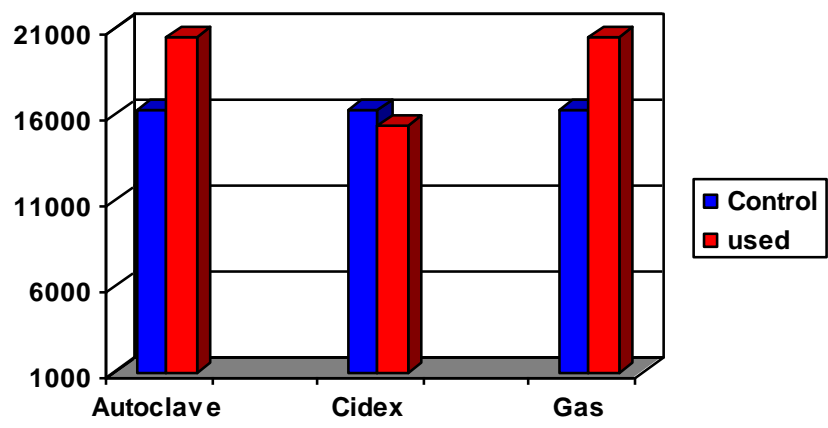

a-Maximum bending strength

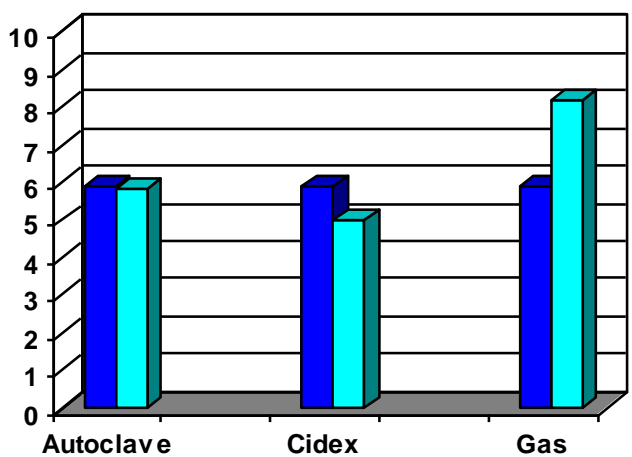

Control

$\square$ used

b- Maximum deflection.

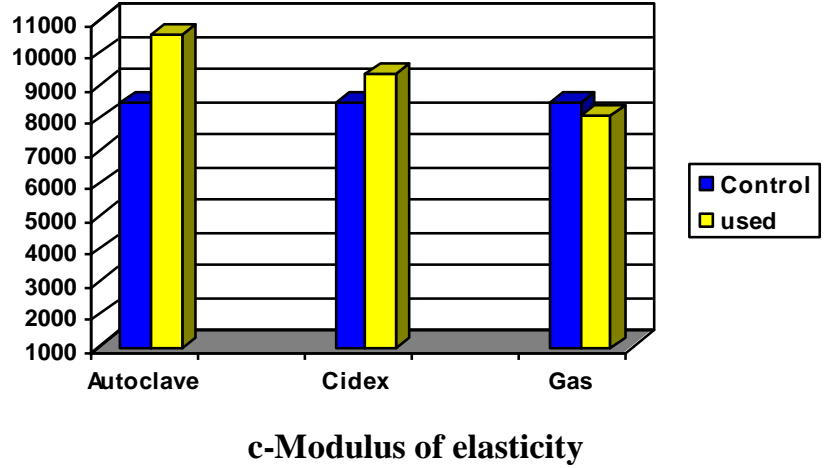

Figure 2: Comparison between control and clinically used sterilized nickel titanium arch wire groups a-maximum bending strength b- maximum deflection c- Modulus of elasticity 
Table 3 and figure 3 compare the means, standard deviation values and results of ANOVA and Duncan's test of the maximum bending strength, maximum deflection and modulus of elasticity between unused and clinically used arch wires groups

Table 3: The means, standard deviation values of the maximum bending strength, maximum deflection and modulus of elasticity between the unused sterilized and the clinically used sterilized arch wires

\begin{tabular}{|c|c|c|c|c|c|c|}
\hline Measurement & \multicolumn{2}{|c|}{$\begin{array}{c}\text { Maximum } \\
\text { bending }\end{array}$} & \multicolumn{2}{c|}{$\begin{array}{c}\text { Maximum } \\
\text { deflection }\end{array}$} & \multicolumn{2}{c|}{$\begin{array}{c}\text { Modulus of } \\
\text { elasticity }\end{array}$} \\
\cline { 2 - 7 } & $\begin{array}{c}\text { Mean } \\
\text { (MPa) }\end{array}$ & SD & $\begin{array}{c}\text { Mean } \\
\text { (mm) }\end{array}$ & SD & $\begin{array}{c}\text { Mean } \\
\text { (MPa) }\end{array}$ & SD \\
\hline $\begin{array}{c}\text { Autoclave sterilization } \\
\text { Group I }\end{array}$ & $15684.2^{\mathrm{a}}$ & 1786.1 & 5.6 & 0.9 & 8441.3 & 570.5 \\
\hline $\begin{array}{c}\text { Cold chemical disinfection } \\
\text { (CIDEX) Group III }\end{array}$ & $16105.1^{\mathbf{a}}$ & 108 & 8.6 & 1.9 & 5780.6 & 1163.6 \\
\hline $\begin{array}{c}\text { Gas sterilization } \\
\text { Group V }\end{array}$ & $17491.6^{\mathbf{a}}$ & 690.4 & 6.4 & 0.5 & 8285 & 409.7 \\
\hline $\begin{array}{c}\text { Autoclave sterilization } \\
\text { Group II }\end{array}$ & $20520.7^{\mathbf{b}}$ & 1555.3 & 5.8 & 0.3 & 10529.7 & 3126.5 \\
\hline $\begin{array}{c}\text { Cold chemical } \\
\text { disinfection (CIDEX) } \\
\text { Group IV }\end{array}$ & $15284.6^{\mathbf{a}}$ & 3063.7 & 5.02 & 0.5 & 9349.4 & 2797.1 \\
\hline $\begin{array}{c}\text { Gas sterilization } \\
\text { Group VI }\end{array}$ & $20498.7^{\mathbf{b}}$ & 2195.3 & 8.2 & 3.5 & 8067.6 & 2251 \\
\hline $\boldsymbol{P}$-value & $0.011^{*}$ & \multicolumn{2}{|c|}{0.122} & & 0.055 \\
\hline
\end{tabular}

SD: Standard Deviation, *: Significant at $\mathrm{P} \leq 0.05$, Means with different letters are statistically significantly different.

There was no statistically significant difference between unused sterilized and clinically used sterilized arch wire groups as regards maximum deflection $(P=0.122)$ and the modulus of elasticity $(P=0.055)$.

As regards the maximum bending strength Duncan's test showed that there was a higher signicant difference values of the autoclave and the gas sterilization groups than the control and cold chemical disinfection groups $(\mathrm{P}=0.011)$. 


\section{Egyptian}

Orthodontic Journal
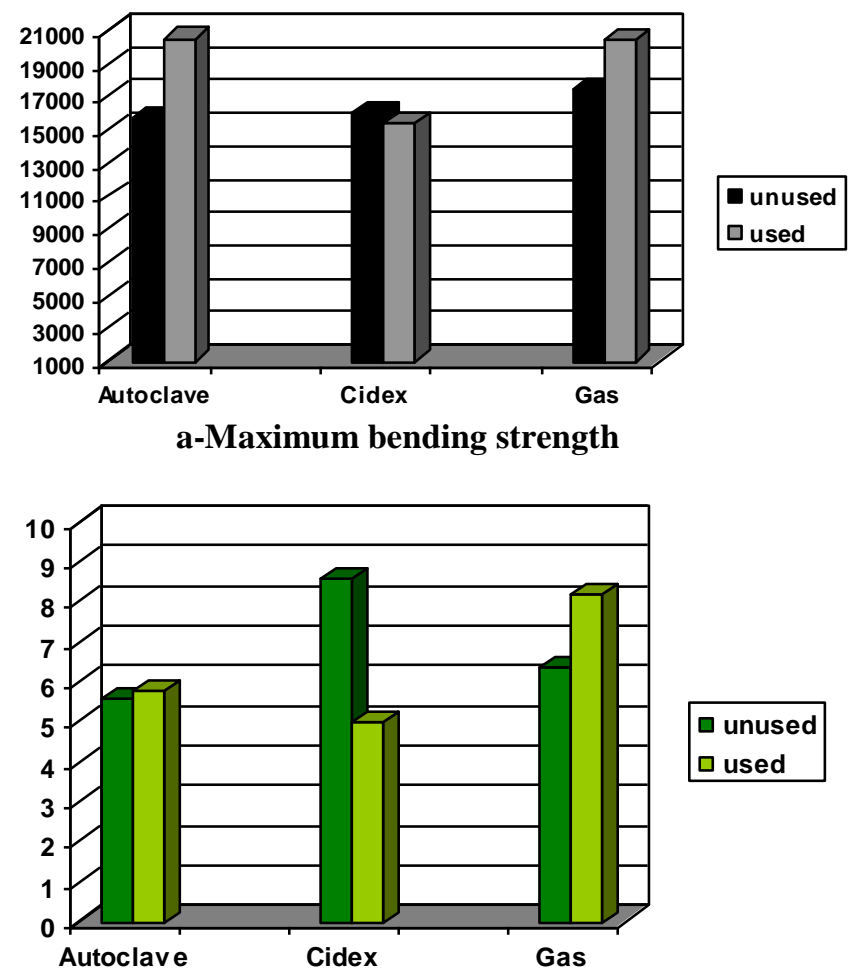

b- maximum deflection

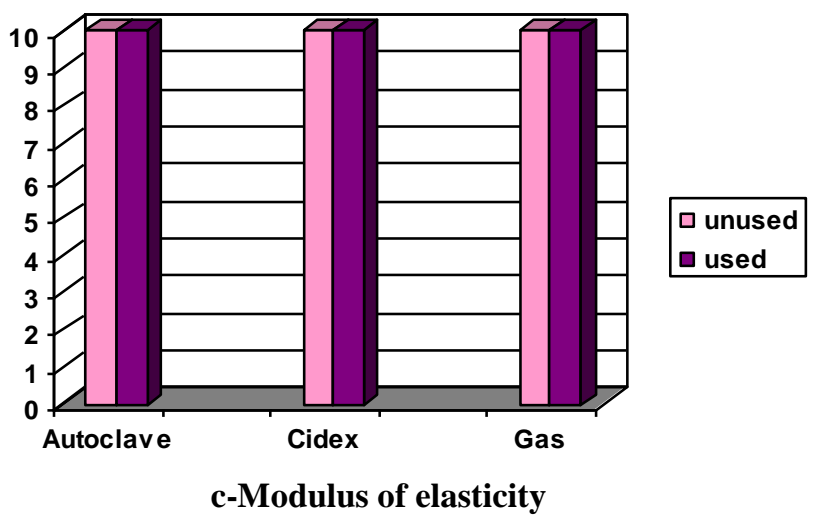

Figure 3: Comparison of the maximum bending strength, maximum deflection and modulus of elasticity between the unused and the clinically used sterilized nickel titanium arch wire groups a- maximum bending strength $b$ - maximum deflection c- Modulus of elasticity 
Egyptian

Orthodontic Journal

\section{II- The atomic force microscopy (AFM) results:}

The AFM image of the control group figure 4 showed the striation present on the surface that resulting from the process of drawing the arch wires during manufacturing. AFM topography of this specimen represented average surface roughness (Ra) $31.31 \mathrm{~nm}$.

Figures 5 showed that the changes in surface topography with disappearance of the normal striations of the passive layer was apparent with an increase of the average surface roughness $(\mathrm{Ra}) 33.01 \mathrm{~nm}$. after cold chemical disinfection solution (CIDEX).

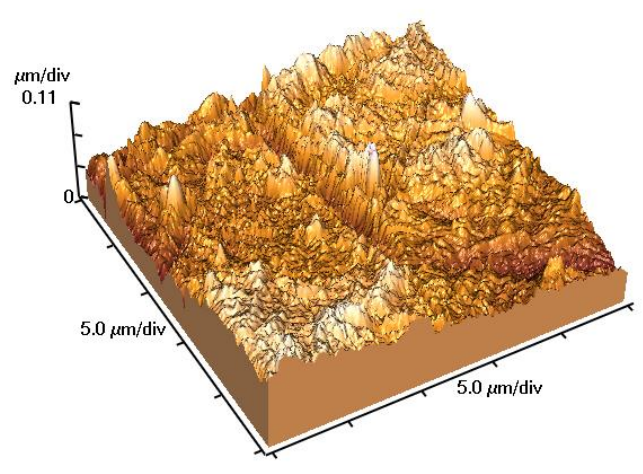

Figure 4: Three dimensional image of AFM of the control group.

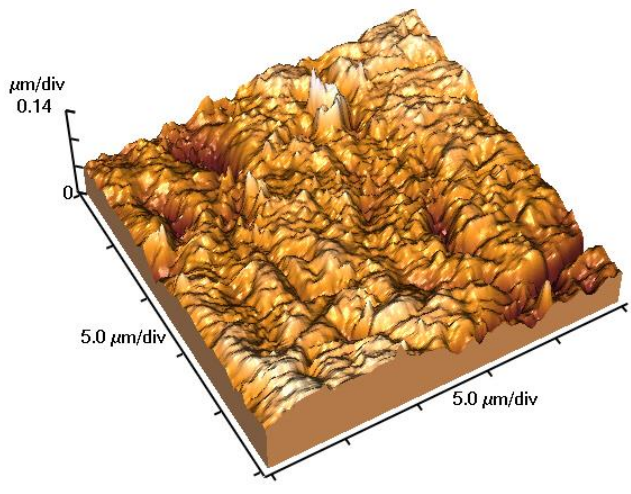

Figure 5: Three dimensional image of AFM of the cold chemical disinfection group.

\section{III- The EDX results:}

The EDX analysis results showed that the elements of the outermost surface of the passive film on all nitinol arch wires were all the same as recorded in their tables below after different method of sterilization. A representative specimens for the control and the cold chemical disinfection solution are shown in figures 6 and 7. 
Egyptian

Orthodontic Journal

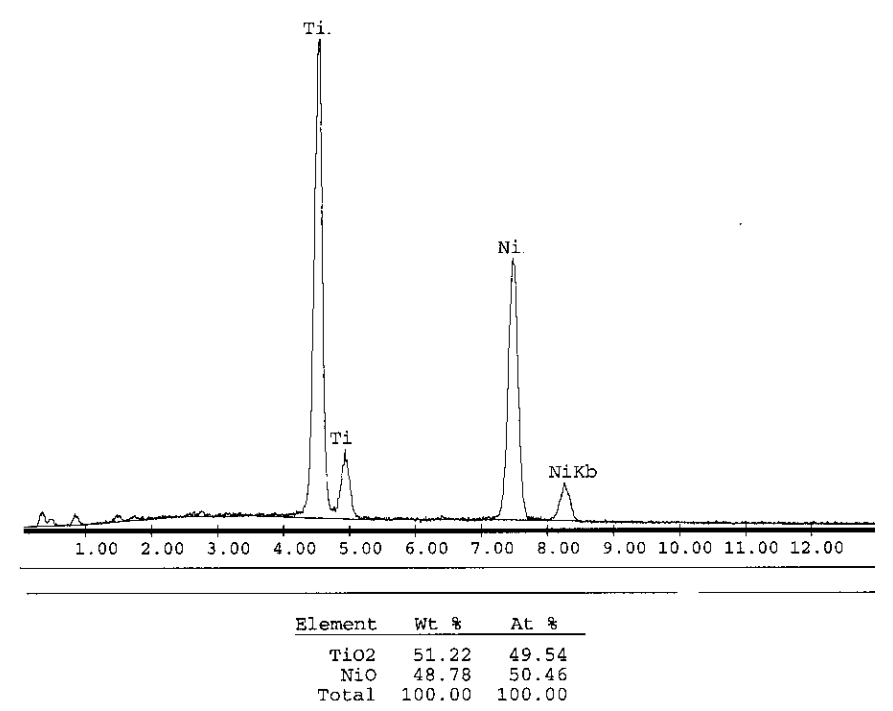

Figure 6: Elemental analysis of the passive layer of the control group .

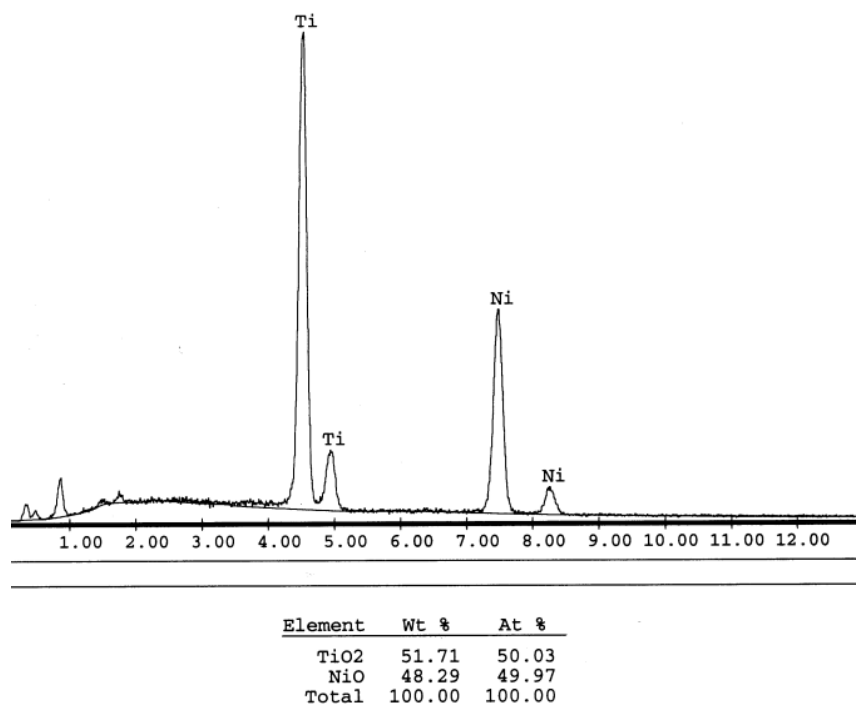

Figure 7: Elemental analysis of the passive layer of the cold chemical disinfection nitinol arch wire. 
Egyptian

Orthodontic Journal

\section{DISCUSSION}

Due to the fact that orthodontic treatment is based upon the bending characteristics of a wire, the international agreement was to classify the arch wires according to their elasticity. The wires are divided into linear characteristics (Type 1 wires) and non-linear characteristics (Type 2 wires). When wires with linear elasticity undergo mechanical pressure, they show direct (linear) proportional pressure right up to their material's elastic capacity. All wires belonging to this Type 1 are made of stainless steel, cobalt chrome alloy or titanium alloy. Wires belonging to the non-linear elasticity type 2 wires, e.g. non-proportional elongation when subjected to mechanical pressure, are the superelastic nickel titanium alloys. Nitinol arch wire has been widely used for decades in orthodontics due to its unique mechanical properties, which differ from other metals such as stainless steel. At first, nitinol wire was used because of its low elasticity moduli (1/5 of that of steel), its extraordinarily large linear elasticity and its reversibility. Originally, the superelasticity of these wires was suppressed using the cold working method. In the last few years, selection of specific transformation temperature has been possible to influence nitinol alloy wires to respond in a non-linear elastic manner when stressed (traction or bending) at body temperature. During bending, the elongation value does not increase in a linear manner, but curves to a flexural force plateau, and then increases without any considerable increase in force. Once the pressure is released, the effect is reversible with the difference that the flexural force plateau is lower than that of under pressure condition this is known as the superelasticity of nitinol. With the nickel titanium alloys used in orthodontics, the existing crystalline structure (cubic space lattice structure) created at higher temperatures, converts into a hexagonal dense crystalline structure at the so called critical transformation temperature range (TTR). The high temperature phase is known as austenitic and the lower temperature phase is known as martensitic. When the crystallographic transformation occurs, the alloy shows dramatic changes in its modulus of elasticity, as a result of alteration in electron bonding. For example, a bent wire in a martensitic state will re-adjust into its original form when heated above the transformation temperature. This phenomenon is known as the shape memory effect. A martensitic transformation can also be initiated during mechanical force in the austenitic phase, when the force is exerted at a temperature just above the transformation temperature (stress induced martensitic structure). In this state, the nitinol wire has also a superelastic characteristics. As determined in the ISO/CD15841, the mechanical properties of type 2 wires with non-linear elasticity, e.g. the superelastic nitinol wires, must only be determined using the 3 point flexural test ${ }^{21,22,23}$. 
Almost no macroscopic shape change is detectable on the transformation, unless there is application of an external force. The martensite shape can be deformed easily to a single orientation by a process known as de-twinning to previously detwinned martensite, when there is exaggerated application type of shear (flipping over). The nitinol alloy is more ductile in the martensitic phase than the austenite phase ${ }^{24}$.

The desirable mechanical properties of nickel-titanium alloy wires and their relatively high cost has prompted many clinicians to recycle these wires. Clinical recycling exposes the wires to several weeks or months of mechanical stresses, elements of the oral environment, as well as sterilization between uses. As previously mentioned the transition from the austenitic to martensitic phase can occurs as a result of the application of stress, such as stresses applied during orthodontic treatment. In most metals, when an external force exceeds a given amount, mechanical slip is induced within the lattice causing permanent deformation; however, with nitinol alloys a stress-induced martensitic transformation occurs, rather than slip. These applied stresses also cause volumetric change associated with the transition from one phase to the other and an orientation relation is developed between the phases.

When comparing the maximum bending strength, the maximum deflection and the modulus of elasticity in this study between the control group and the unused sterilized arch wires to show the effect of using different sterilization methods on the properties of the alloy (figure 1 and table 1), the results showed a significantly drop in the modulus of elasticity of the alloy when using cold chemical disinfection solution (CIDEX). Although the EDX analysis results (figures 6 and 7) showed that the elemental structure of the outermost surface of the passive film on all nitinol arch wires was the same even with the most aggressive attack by cold chemical sterilization. The atomic force microscope results (figures 4 and 5) showed severe surface roughness for the outer passive layer disinfected with the cold chemical disinfection solution. This may be due to CIDEX which, is a strong chemical disinfection solutions, may attack the surface of the alloy, diffuses through the surface oxide increasing the interatomic distance and adversely affects the bonding between the material molecules encouraging phase transformation and reduce the modulus of elasticity of the material. As the sequence of the phase transformation is the alteration of bonding and dramatic change of the modulus of elasticity. This was in agreement with Oshida et al 1992 and Shabaloveskaya 2002 ${ }^{25.26}$.

Sterilization using autoclave and gas showed insignificant changes in maximum bending strength, maximum deflection and modulus of elasticity 
between the control and the unused sterilized arch wires. This might be due to the low temperature of the autoclave $\left(134.4^{\circ} \mathrm{C}\right)$ as well as gas sterilization $\left(54.44^{\circ} \mathrm{C}\right)$ which, does not affect the bending properties of arch wires. This was in agreement with Poehler OEM 1983, Croppy et al 1996 and Thompson $2000^{27,5,3}$. Therefore, both short term autoclaving in steam and gas can be used safely to sterilize nitinol arch wires.

Comparing the maximum bending strength, the maximum deflection and the modulus of elasticity between the control and the clinically used sterilized arch wires (figure 2 table 2), as well as between the unused sterilized and the clinically used sterilized arch wires (figure 3 table 3 ) in this study, showed a significant increase in the maximum bending strength for the clinically used autoclave and gas arch wires which, clarify the effect of cold working. The different working processes change the grain size and energy state of the metal and cause surface heterogeneity ${ }^{27}$. This may be due to excessive plastic deformation, during usage of the arch wires inside the patient mouth which, increases more and more the strength of a wire since arch wires are cold worked structure in which the amount of grain boundaries increase which hinders the movement of dislocation resulting in increases the strength of a structure. Cold working, destroys the martensitic plateau on the stress strain curve of nitinol alloy. Thus, a material cold worked $20 \%$ in the martensite has a very high yield strength. Cold work introduces a high density of random dislocations that impede the mobility of the twin boundaries (characteristic feature of the plastic deformation of nitinol). The obtained results were in agreement with Duerig TW 1990, Craig 2002 and Anusavice K 200328,29,30

\section{CONCLUSIONS}

Within the limitation of this study, the following can be concluded:

1- It is worth to reuse the nickel-titanium arch wires due to its high cost.

2- Autoclave and gas sterilization did not affect the nickel titanium alloy.

3- Chemical sterilization may alter the topography of nickel titanium alloy and consequently affects its bending property.

4- Mechanical forces during the usage affect the maximum bending strength of arch wires.

However further investigations are to be suggested to study the effect of these sterilization methods on the corrosion behavior of orthodontic arch wires. 
Egyptian

Orthodontic Journal

\section{REFERENCES}

1. Frank RP, Brudvik JS, Nicholls JI. A comparison of the flexibility of wrought wire and cast circumferential clasps. J Prosthet Dent 49:471-6, 1983.

2. Andreasen G, Wass K, Chan KC A review of superelastic and thermodynamic Nitinol wire. Quintessence International 9, 623-6, 1985.

3. Thompson S.A An overview of nickel-titanium alloys used in dentistry. International Endodontic Journal 33, 297-310, 2000.

4. Edie JW, Andreasen GF, Zaytoun MP Surface corrosion of Nitinol and stainless steel under clinical conditions. Angle Orthodontics 51, 319-24, 1981.

5. Croppy OP, Davies EH and Jones SP. The effects of cross-infection control procedures on the tensile and flexural properties of superelastic nickel-titanium wires. Br J orthodo 23 (1): 37-41, 1996.

6. Kapila S, Haugen JW and Watanab LG. Load-deflection characteristics of nickel-titanium alloy wires after clinical recycling and dry heat sterilization. Am J Orthod Dentofacial Orthop. 102 (2) 120-6, 1992.

7. Pernier C, Grosgogeat B, Ponsonnet L, Benay $G$ and Lissac $M$ Influence of autoclave sterilization on the surface parameters and mechanical properties of six orthodontic wires. European J Orthod 27 (1): 72-81 2005.

8. Smith GA, Von Fraunhofer JA and Casey GR. The effect of clinical use and sterilization on selected orthodontic arch wires. Am J Orthod Dentofacial Orthop 102: 153-9 1992

9. Harris EF, Newman SM, Nicholson JA. Nitinol arch wire in a simulated oral environment: changes in mechanical properties. Am $\mathrm{J}$ Orthod Dentofacial Orthop.; 93:508-513, 1988.

10. Rondelli G, Vicentini B. Evaluation by electrochemical tests of the passive film stability of equiatomic Ni-Ti alloy also in presence of stress-induced martensite. J Biomed Mater Res. 51:47-54, 2000.

11. ADA Council on Scientific Affairs and ADA Council on Dental Practice. Infecion control recommendations for the dental office and the dental laboratory. J Am Dent Assoc 127:672-80, 1996. 
12. Hastreiter RJ, Molinari JA, Falken MC, Roesch MH, Gleason MJ, Merchant VA. Effectiveness of dental office instrument sterilization procedures. J Am Dent Assoc 122:51-6, 1991.

13. Andres MT, Tejerina JM, Fierro JF. Reliability of biologic indicators in a mail-return sterilization-monitoring service: a review of 3 years. Quintessence Int 26:865-70, 1995.

14. Miller CH. Cleaning, sterilization and disinfection: basics of microbial killing for infection control. J Am Dent Assoc 124:48-50, 1993.

15. Piekarski JM, Toporowski E. A custom implant instrument organizer for prosthetics. J Prosthet Dent 76:644, 1996.

16. Buckthal JE and Kusy RP. Effects of cold disinfectants on the mechanical properties and the surface topography of nickel-titanium arch wires. Am J Orthod Dentofacial Orthop 94: 117-122 1988.

17. Ma T, Johnson GH, Gordon GE. Effects of chemical disinfectants on surface characteristics and color of three fixed prosthodontic crown materials. J Prosthet Dent 82:600-7, 1999.

18. Adler P.H., Herreria S., Kostur G., Carpenter S., Poncet P., Wu M., and Discipio W. The role of alkaline cleaning solutions and cl-containing lubricants on pitting corrosion in niti alloys. Memry Corporation 3 Berkshire Blvd. Bethel, CT 06801. 1PercuSurge, Inc. 540 Oakmead Parkway Sunnyvale, CA 94086

19. Shigley JE and Mischke CR. Mechanical engineering design. McGraw-Hill international editions Mechanical engineering series $5^{\text {th }}$ edition 1989.

20.SPSS (Statistical Package for Scientific Studies) for Windows, Inc., Chicago, IL, USA.

21. Wires and Arches Tested in daily practice For successful treatment results. Wire manual printed by Dentaurun Germany 989-561-20 04/05/CR1. Dentaurun Turnstraße 31. 75228 Ispringen. Germany.

22. Wang FE, Pickart SJ, Alperin HA Mechanism of the TiNi martensitic transformation and the crystal structures of TiNi-II and TiNi-III phases. Journal of Applied Physics 43, 97-112, 1972

23. Lee JH, Park JB, Andreasen GF, Lakes RS Thermomechanical study of NiTi alloys. Journal of Biomedical Materials Research 22, 573-88, 1988. 
Egyptian

Orthodontic Journal

24. Brockhurst P, Hsu E. Hardness and strength of endodontic instruments made from NiTi alloy. Australian Endodontic Journal 24:115-9, 1998.

25. Oshida Y, Sachdeva RC and Miyazaki S Microanalytical characterization and surface modification of TiNi orthodontic arch wires. Biomed.Mater.Eng. 2: 51-69, 1992.

26. Shabalovskaya SA. Surface, corrosion and biocompatibility aspects of Nitinol as an implant material. Bio-Med. Mater. Eng. 12 69-109, 2002.

27. Poehler OEM. Degradation of metallic orthopedic implants. In: Rubin LR (ed.). Biomaterials in reconstructive surgery, C.V. Mosby Company, St. Louis, p 158-228, 1983.

28. Duerig, T. W. Engineering aspects of shape memory alloys. ButterworthHeinemann, London, England. 1990.

29. Craig R.G. and Powers JM: Restorative dental materials $11^{\text {th }}$ ed., pp $175-177$ the C.V. Mosby Company, 2002

30. Anusavice, K.J.: Phillips' Science of Dental Materials $11^{\text {th }}$ ed., pp 635 - 637 W.B. Saunders Company, Elsevier Science (USA). 2003. 